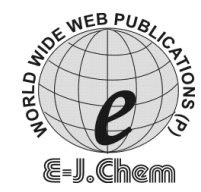

http://www.e-journals.net

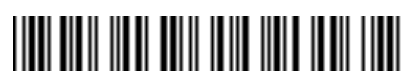

ISSN: 0973-4945; CODEN ECJHAO

E-Journal of Chemistry

Vol. 4, No. 3, pp. 376-380, July 2007

\title{
Synthesis and Characterization of 6-Carbamoyl-1,2-dihydropurines
}

\author{
ASIEH YAHYAZADEH* and FATEMAH HOSSAINI \\ Department of Chemistry, \\ University of Guilan, P.O. Box 1914, Rasht, Iran. \\ yahyazadehphd@yahoo.com
}

Received 13 December 2006; Accepted 10 January 2007

\begin{abstract}
The aromatic amines react readily with (Z)- $N$-(2-amino-1,2dicyanovinyl)formimidate (4) to give the amidines (5a-b), which cyclize in the presence of DBU (1,8-diazabicyclo[5.4.0]undec-7-ene) to give the corresponding 2-(5-Amino-1-phenyl- $1 \mathrm{H}$-imidazol-4-yl)-2-iminoacetonitrile (6a-b), which can be isolated. In the presence of aldehyde the formimidoylimidazole lead to novel 6-carbamoyl-1,2-dihydropurines (8a-b). All compounds have been fully characterized by spectroscopic data.
\end{abstract}

Keywords: Formimidoylimidazole, Aromatic amines, Imidate, Diaminomaleonitrile, Purine-6carbooxamide

\section{Introduction}

Since the discovery of acyclovir great research effort has been devoted to the synthesis of new acyclic nucleoside analogues as potential anti-herpes (HSV) and anti-human cytomegalovirus (HCMV) agents, ${ }^{1}$ potent antiviral activities have been found for 'carboacyclic' nucleoside analogues such as $\mathbf{1},{ }^{1,2}$ and purine derivatives with simple 9-hydroxyalkyl substituents, such as $\mathbf{2}$ and $\mathbf{3}$, have biological activity ${ }^{3-8}$.

As part of a general study ${ }^{9-14}$ of the synthesis of (C-cyanoformimidoyl)imidazole-5amines we now report the preparation and reaction of new 1-phenyl-4-(C-cyano formimidoyl)imidazole and 1-benzyl-4-(C-cyanoformimidoyl)imidazole. These have been found to be useful intermediates for the synthesis of new compounds 9-phenyl and 9-benzyl1, 2-dihydropurine $\mathrm{e}^{15-19}$. 
<smiles></smiles>

1<smiles>[R]c1nc2c([X])nc(N)nc2[nH]1</smiles>

$\left.2 \mathrm{X}=\mathrm{NH}_{2} \mathrm{HCl} ; \mathrm{R}=\mathrm{CH}(\mathrm{CHMeOH}) \mathrm{CH}_{2}\right)_{5} \mathrm{CH}_{3}$ $3 \mathrm{X}=\mathrm{OH} ; \mathrm{R}=\mathrm{CH}(\mathrm{CHMeOH})\left(\mathrm{CH}_{2}\right)_{5} \mathrm{CH}_{3}$

\section{Experimental}

All solvents purified and dried using established procedures. The ${ }^{1} \mathrm{H}$ NMR spectra were recorded on Bruker XL $500(500 \mathrm{MHz})$ instruments, ${ }^{13} \mathrm{C}$ NMR spectra on DRX-500 AVANCE spectrometer, and IR spectra on a Shimadzu IR-470 spectrophotometer. Mass spectra were recorded on a Kratos Concept instrument. The melting points were measured on an Electrothermal digital melting point apparatus and are uncorrected.

General procedure for the preparation of the 2-(5-Amino-1-phenyl-1H-imidazol-4$y$ l)-2-iminoacetonitrile (6a-b)

A suspension of the corresponding aryl-(Z)-N-[2-amino-1, 2-dicyanovinyl]formamidine $(\mathbf{5 a}-\mathbf{b})^{6-8}(1.00 \mathrm{~g})$ in dry ethanol $(8 \mathrm{~mL})$ was added DBU (9 drops). The mixture was stirred under an argon atmosphere at room temperature for 0.5-3 h. After this time, TLC showed that all the amidine had been consumed. The reaction mixture was then filtered off, washed with dry diethyl ether and dried under vacuum to give $\mathbf{6 a - b}$.

\section{2-(5-Amino-1-phenyl-1H-imidazol-4-yl)-2-iminoacetonitrile $\left(6 a, \mathrm{C}_{11} \mathrm{H}_{9} \mathrm{~N}_{5}\right)$}

Recrystallization of the product from dry diethyl ether and air-dried to give yellow crystals of $\mathbf{6 a}$ (0.7 g, 2.7 mmol, 71\%). Mp 114-116 ${ }^{\circ} \mathrm{C}$ (decomp.); IR (KBr): 3420, 3360, 3210, 3290, 3160, 2200, 1650, 1590, 1550, 1365, 1260, $1210 \mathrm{~cm}^{-1} ;{ }^{1} \mathrm{H}$ NMR (500 MHz, DMSO-d $\left.\mathrm{d}_{6}\right): \quad \delta=6.64$ (s, $2 \mathrm{H}, \mathrm{NH}_{2}$ ), 6.70-6.84 (m, 5H, Ar-H), 7.20 (s, 1H, H-imidazole), 9.88 (br. s, $1 \mathrm{H}, \mathrm{NH}$ ) ppm; ${ }^{13} \mathrm{C}$ NMR (75 MHz, DMSO-d ${ }_{6}$ ): $\delta=117.4,120.4,128.8,132.6,134.0,136.1,137.9,147.1,147.9$ ppm; MS (EI, $70 \mathrm{Ev}): m / z(\%) 212(3.9)(\mathrm{M}+1)^{+}, 211(13.7)(\mathrm{M})^{+}, 78(14.2)$.

\section{2-(5-Amino-1-benzyl-1H-imidazol-4-yl)-2-iminoacetonitrile (6b, $\left.\mathrm{C}_{12} \mathrm{H}_{11} \mathrm{~N}_{5}\right)$}

Recrystallization of the product from diethyl ether give pale green crystals of $\mathbf{6 b}(0.62 \mathrm{~g}$, $2.57 \mathrm{mmol}, 62 \%)$. M.p. $136-137{ }^{\circ} \mathrm{C}$ (decomp); IR (KBr): 3320, 3210, 3190, 2220, 2210 , $1640,1570,1510,1450,1280,860,815,820 \mathrm{~cm}^{-1} ;{ }^{1} \mathrm{H}$ NMR (500 MHz, DMSO-d $\left.\mathrm{d}_{6}\right): \delta=5.45$ (s, 2H, $\mathrm{CH}_{2}$ ), 6.10 (br. s, $2 \mathrm{H}, \mathrm{NH}_{2}$ ), 6.95-7.09 (m, 5H, Ar-H), 7.14 (s, 1H, H-imidazole), 9.80 (br. s, $1 \mathrm{H}, \mathrm{NH}) \mathrm{ppm} ;{ }^{13} \mathrm{C}$ NMR $\left(75 \mathrm{MHz}, \mathrm{DMSO}-\mathrm{d}_{6}\right): \delta=49.7,117.5,120.2,131.2$, 131.7, 132.4, 136.4, 140.4, 147.1, 148.3 ppm; MS (EI, $70 \mathrm{Ev}): \mathrm{m} / \mathrm{z}(\%) 226(100)(\mathrm{M}+1)^{+}$, $225(11.6)(\mathrm{M})^{+}, 199(20.6), 91(20.8)$.

Preparation of 2-(3-nitrophenyl)-9-phenyl-2,9-dihydro-1H-purine-6-carboxamide $\left(8 a, \mathrm{C}_{18} \mathrm{H}_{14} \mathrm{~N}_{6} \mathrm{O}_{3}\right)$

A suspension of the imidazole $(0.4 \mathrm{~g}, 1.8 \mathrm{mmol})$ and 3-nitrobenzaldehyde $\left(5 \mathrm{~cm}^{3}\right)$ in methanol $(5 \mathrm{~mL})$ was stirred at room temperature overnight. The orange solid was filtered, washed with diethyl ether and dried to give 2- (3-nitrophenyl)-9-phenyl-2,9-dihydro- $1 \mathrm{H}$ - 
purine-6-carboxamide (8a) $(0.47 \mathrm{~g}, 1.5 \mathrm{mmol}, 81 \%)$. Mp 172-174 ${ }^{\circ} \mathrm{C}$ (decomp.); IR (KBr): 3399, 3355, 3215, 3100, (N-H str.), 2220, 2210 (CN str.), $1695(\mathrm{C}=\mathrm{O}), 1660$ (C=N str.), 1560 (N-H bend), 1510, 1450, 1270, 860, $800 \mathrm{~cm}^{-1} ;{ }^{1} \mathrm{H}$ NMR (500 MHz, DMSO-d 6 ): $\delta=6.85-6.97(\mathrm{~m}, 5 \mathrm{H}, \mathrm{Ar}-\mathrm{H}), 7.12-7.30(\mathrm{~m}, 3 \mathrm{H}, \mathrm{Ar}-\mathrm{H}), 7.50$ (s, 1H, H-imidazole), 7.69-7.72 (br. s, 2H, $\mathrm{NH}_{2}$ ), 9.60 (br. s, $1 \mathrm{H}, \mathrm{NH}$ ) ppm; ${ }^{13} \mathrm{C}$ NMR $\left(75 \mathrm{MHz}, \mathrm{DMSO}-\mathrm{d}_{6}\right.$ ): $\delta=76.2,136.4$, 122.2, 159.8, 148.4, 166.4, 124.4-124.5 ppm; MS (EI, 70 Ev): $m / z(\%) 363(65.5)(\mathrm{M}+1)^{+}$, $362(78)(\mathrm{M})^{+}, 346$ (18.4), 318 (90.6), 316 (60.5), 272 (17.6), 196 (34), 119 (25.1).

Preparation of 9-benzyl-2-(3-nitrophenyl)-2, 9-dihydro-1H-purine-6-carboxamide $\left(8 b, \mathrm{C}_{19} \mathrm{H}_{16} \mathrm{~N}_{6} \mathrm{O}_{3}\right)$

A suspension of the imidazole $(0.5 \mathrm{~g}, 2.2 \mathrm{mmol})$ in 3-nitrobenzaldehyde $\left(8 \mathrm{~cm}^{3}\right)$ was stirred at room temperature. After 20 minutes, an orange solid was started to precipitate, and reaction was complete after $3 \mathrm{~h}$. Additional of the chloroform and partial removal of the solvent on the rotary evaporator led to an orange solid, which was washed with chloroform and diethyl ether, and identified as 9-benzyl-2-(3-nitrophenyl)-2,9-dihydro-1H-purine-6-carboxamide (8b) (0.52 g, 1.6mmol, 72\%). An analytical sample was obtained after flash chromatography (silica 60; dry acetone eluent) which gave bright orange crystals. M.p. $182-186{ }^{\circ} \mathrm{C}$ (decomp.); IR (KBr): 3310, 3220, 3170 (N-H str.), 2220, 2200 (CN str.), 1710 (C=O), 1630 (C=N str.), 1570 (N-H bend), 1520, 1460, 1280, 850, $810 \mathrm{~cm}^{-1} ;{ }^{1} \mathrm{H}$ NMR (500 MHz, DMSO-d $\left.{ }_{6}\right): \delta=4.95(\mathrm{~s}, 2 \mathrm{H}, \mathrm{H}-$ 2), 6.92-7.00 (m, 5H, Ar-H), 7.10-7.30 (m, 4H, Ar-H), 7.42 (s, 1H, H-imidazole), 7.83-7.85 (br. s, $2 \mathrm{H}, \mathrm{NH}_{2}$ ), 9.67 (br. s, $\left.1 \mathrm{H}, \mathrm{NH}\right) \mathrm{ppm} ;{ }^{13} \mathrm{C}$ NMR (75 MHz, DMSO- $\mathrm{d}_{6}$ ): $\delta=24.5,76.5$, 137.2, 122.4, 160.3, 148.7, 166.8, 123.6-14.2 ppm; MS (EI, 70 Ev): m/z (\%) 377 (91.5) $(\mathrm{M}+1)^{+}, 376(100)(\mathrm{M})^{+}, 332(8.9), 330(1.8), 286(3.2), 210(7.6 \%)$.

\section{Results and Discussion}

Formimidate (4) was prepared in high yield from diaminomaleonitrile and triethyl orthoformate, according to a previously described procedure ${ }^{6-8}$. Having obtained the imidate (4) in good yield (94\%) it was then treated with aryl or benzylamine in a 1:1 molar ratio in ethanol in the presence of a catalytic amount of anilinium chloride ${ }^{8,9}$.

We thus attempted to cyclise the amidines 5a-b to obtain compounds of type $\mathbf{6 a - b}$, in $78 \%$ yield by treatment with DBU (1, 8-diazabicyclo[5.4.0]undec-7-ene) in ethanol. ${ }^{10-12}$ The reaction was followed by TLC. When all the starting material had been consumed filtration and concentration of the filtrate under reduced pressure $\left(\right.$ at $\left.<30^{\circ} \mathrm{C}\right)$ gave $\mathbf{6 a}-\mathbf{b}$ as a pale green solid which were stored under argon at low temperature. It was found that this compound darkens rapidly in solution and decomposes to black oil. Compounds 6a-b would be important intermediates for the synthesis of a range of 9-aryl or benzylpurines and 9-aryl or benzyl-1, 2-dihydropurines ${ }^{7-12}$.

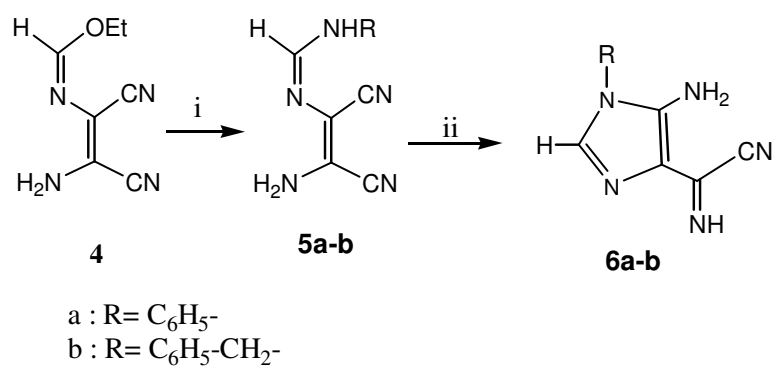

Scheme 1. Reagents and conditions: (i) $\mathrm{RNH}_{2}, \mathrm{ArNH}_{3}{ }^{+} \mathrm{Cl}{ }^{-}$, (ii) $\mathrm{DBU}, \mathrm{EtOH}$, room temp. 
The spectroscopy results obtained on these compounds 6a-b were satisfactory. The ${ }^{1} \mathrm{H}$ NMR spectrum showed the presence of two broad singlet a 6.64 and $9.88 \mathrm{ppm}$ due to the amine protons and a singlet at 7.28 for the $\mathrm{HC}$ proton of the imidazole ring. The ${ }^{13} \mathrm{C} \mathrm{NMR}$ spectrum was fully consistent with the assigned structure. The infrared spectrum confirmed the presence of the $\mathrm{NH}$ and $\mathrm{C}=\mathrm{N}$ stretching vibrations within the region of 3420-3160, and $1650-1640 \mathrm{~cm}^{-1}$ respectively. The infrared spectrum also showed a sharp absorption band at $2220-2200 \mathrm{~cm}^{-1}$ for the $\mathrm{C} \equiv \mathrm{N}$ stretching vibration.

The dihydropurines 8a-b were prepared by stirring a suspension of the corresponding 4-(cyanoformimidoyl)-imidazoles $\mathbf{6 a - b}$ with a slight excess of 3-nitrobenzaldehyde in a small amount of ethanol or methanol at room temperature (Scheme 2). The reactions were monitored by TLC (9: $\left.1 \mathrm{CHCl}_{3}-\mathrm{EtOH}\right)$ and reaction times varied between $20 \mathrm{~min}$ and $24 \mathrm{~h}$. Depending upon the solvent used for the reaction and the rate of precipitation, these dihydropurines can be isolated as solids in color from orange to yellow.

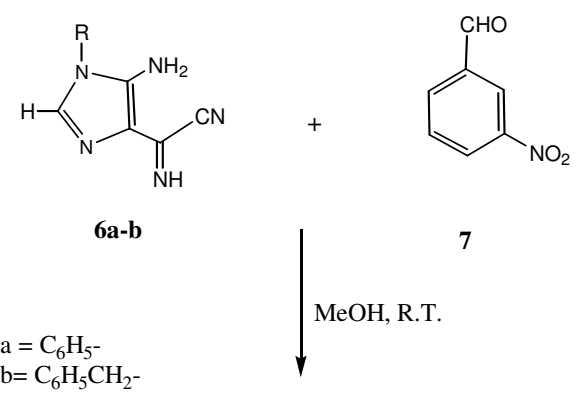<smiles>[R]n1cnc2c1=NC(c1cccc([N+](=O)[O-])c1)NC=2C(N)=O</smiles>

8a-b

\section{Scheme 2.}

Compounds 8a-b were recrystallised from mixture of ethanol/methanol (1:1) and gave pale yellow to off white crystals respectively. These were fully characterized by TLC, IR and ${ }^{1} \mathrm{H}$ NMR, ${ }^{13} \mathrm{C}$ NMR and mass spectroscopy. The infrared spectrum confirmed the presence of the $\mathrm{NH}$ and $\mathrm{C}=\mathrm{N}$ stretching vibrations within the region of $3400-3100$, and $1660-1650 \mathrm{~cm}^{-1}$ respectively. The $\mathrm{C}=\mathrm{O}$ of the amide group appeared at $1695-1710 \mathrm{~cm}^{-1}$ as a strong band. The high resolution mass spectrum gave a molecular ion peak at 363,377 $(\mathrm{M}+1)^{+}$which fits with the expected molecular weight of 362,376 for the dihydropurine (8a-b). In the ${ }^{1} \mathrm{H}$ NMR spectra of the isolated compounds $\mathbf{8 a}$ and $\mathbf{8 b}$, the amide protons were observed in the region of $\delta 7.69-7.85 \mathrm{ppm}$ and in several cases the assignment were confirmed by $\mathrm{D}_{2} \mathrm{O}$ exchange. The $\mathrm{H}-2$ proton appeared as a broad singlet at $\delta 4.95-4.97 \mathrm{ppm}$ and the aromatic protons showed the expected patterns in the range of $\delta 6.85-7.30 \mathrm{ppm}$. The proton of the imidazole ring appeared as a sharp singlet in the range of $\delta 7.42-7.50 \mathrm{ppm}$. The ${ }^{13} \mathrm{C} \mathrm{nmr} \mathrm{spectrum} \mathrm{of} \mathrm{these} \mathrm{dihydropurine} \mathrm{had} \mathrm{the} \mathrm{expected} \mathrm{number} \mathrm{of} \mathrm{bands,} \mathrm{with} \mathrm{the} \mathrm{C-2}$ carbon at $\delta 76.2-76.5, \mathrm{C} 4$ carbon at $\delta 136.4-137.2, \mathrm{C}-5$ carbon at $\delta 122.2-122.4, \mathrm{C}-6$ carbon at $\delta 159.8-160.3, \mathrm{C}-8$ carbon at $\delta 148.4-148.7, \mathrm{C}=\mathrm{O}$ carbon at $\delta 166.4-166.8 \mathrm{ppm}$. 


\section{References}

1 Lockhart C C and Sowell J W Sr, J. Heterocyclic Chem. 1996, 33, 659.

2 Erian A W, Chem. Rev.1993, 93, 1991.

3 Booth B L, Alves M J, Proenca J R P and Fernanda M, J. Chem. Perkin. Trans. 1, 1992, 913.

4 Booth B L, Dias A D, Proenca M F, J. Chem. Soc. Perkin. Trans. 1, 1992, 2119.

5 Booth B L, Freitas A P, Fernanda M and Proenca J R P, J. Chem. Research (S), 1993, 260.

6 Asano S, Itano K, Yamagata Y and Kohda K, Nucleosides \& Nucleotides, 1994, 13, 1453.

$7 \quad$ Moriya O, Minamide H and Urata Y, Synth. Commun. 1984, 1057.

$8 \quad$ Birkett P R and King H, Tetrahedron, 1993, 49, 11029.

9 Ohtsuka Y, J. Org. Chem. 1979, 44, 827.

10 Yahyazadeh A, Pourrostam B and Rabiee M, Bull. Korean. Chem. Soc. 2003, 24, 1723.

11 Yahyazadeh A, Russ. J. Org. Chem. 2003, 39, 1649.

12 Al-Azmi A, Elassar A A, Booth B L, Carpenter A R, Carvalho A and Marrelec E, J. Chem. Soc. Perkin. 1, 2001, 2532.

13 Booth B L, Alves M J, Carvalho A, Eastwood P R and Nezhat L, J. Chem. Soc. Perkin. Trans. 1994, 2, 1949.

14 Yahyazadeh A and Sharifi Z, Phosphorus, Sulfur, and Silicon. 2006, 6, 1339.

15 Yahyazadeh A and Booth B L, Synth. Commun. 2002, 21, 3241.

16 Yahyazadeh A and Booth B L, Synth. Commun. 2001, 31, 3225.

17 Al-Azmi A, Elassar A A and Booth B L, Tetrahedron.2003, 59, 2749.

18 Booth B L, Alves M J, Proenca J R P and Fernanda M, J. Chem. Soc. Perkin. Trans. 1, 1990, 1705.

19 Booth B L, Alves M J, Proenca J R P and Fernanda M, J. Hetrocyclic. Chem. $1995,32,457$. 


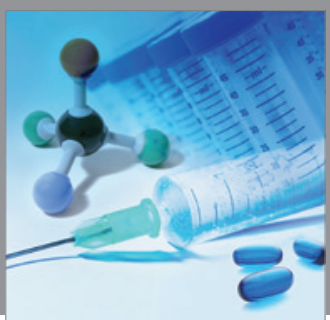

International Journal of

Medicinal Chemistry

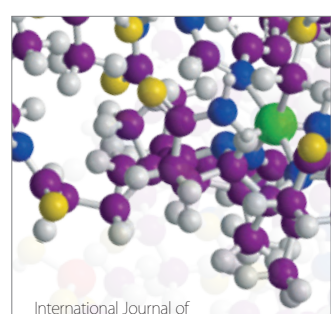

Carbohydrate Chemistry

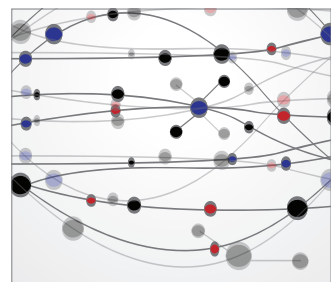

The Scientific World Journal
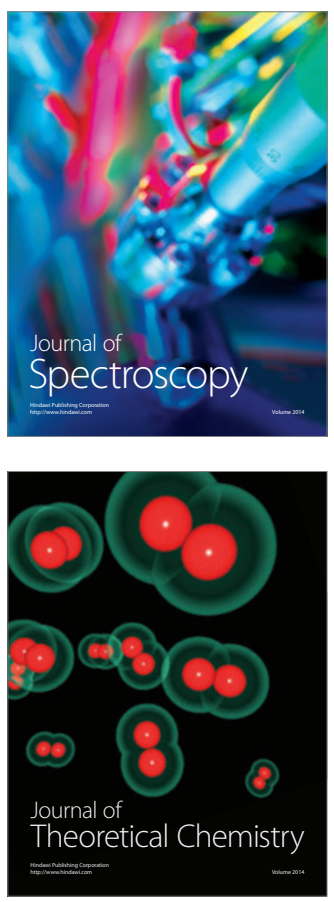
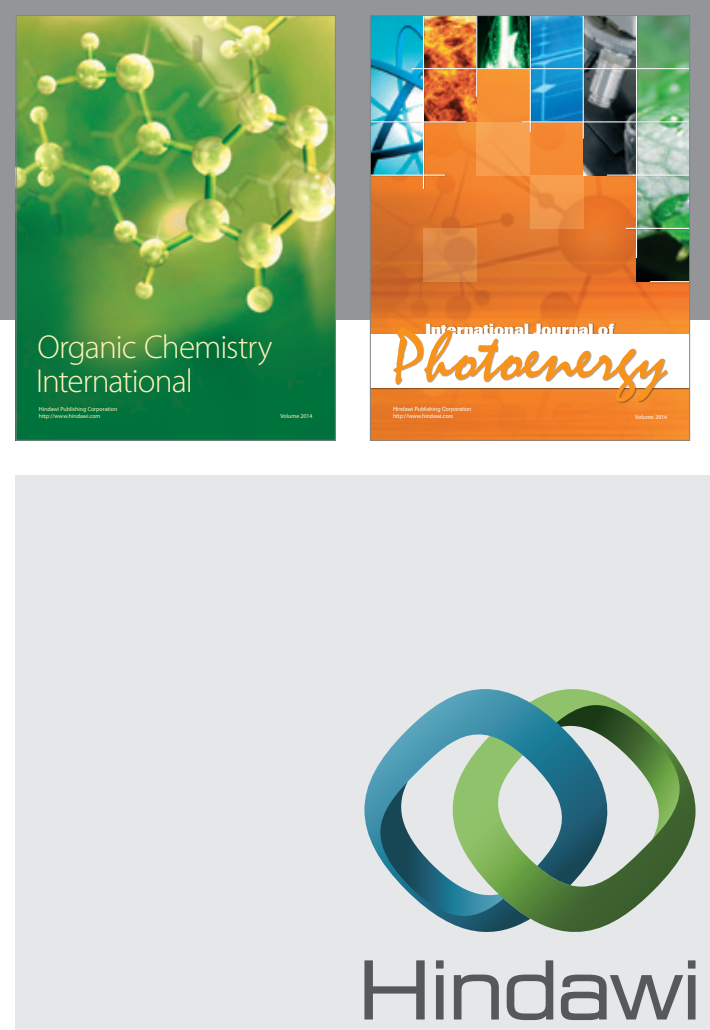

Submit your manuscripts at

http://www.hindawi.com
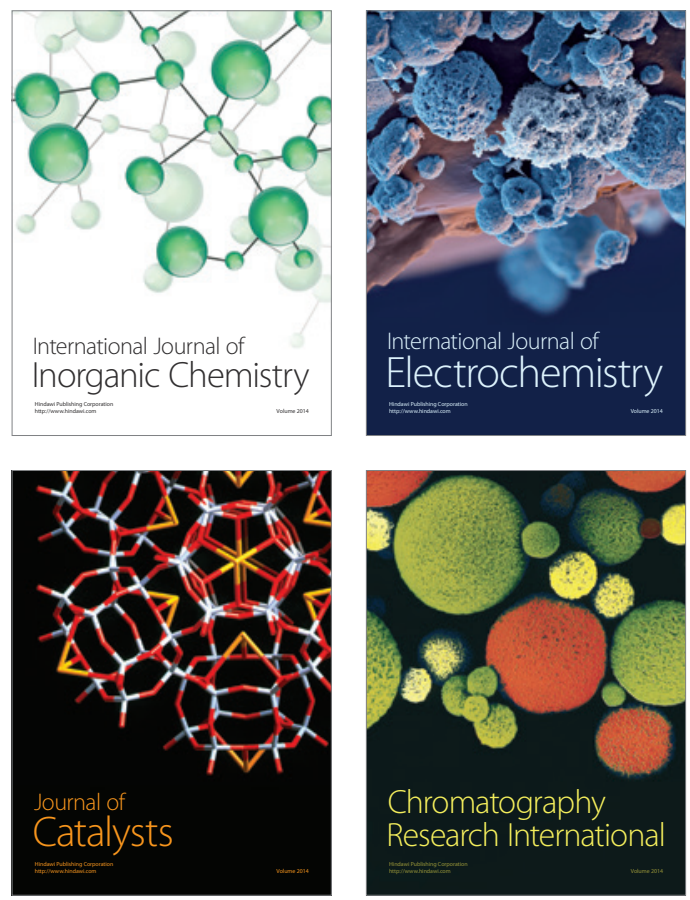
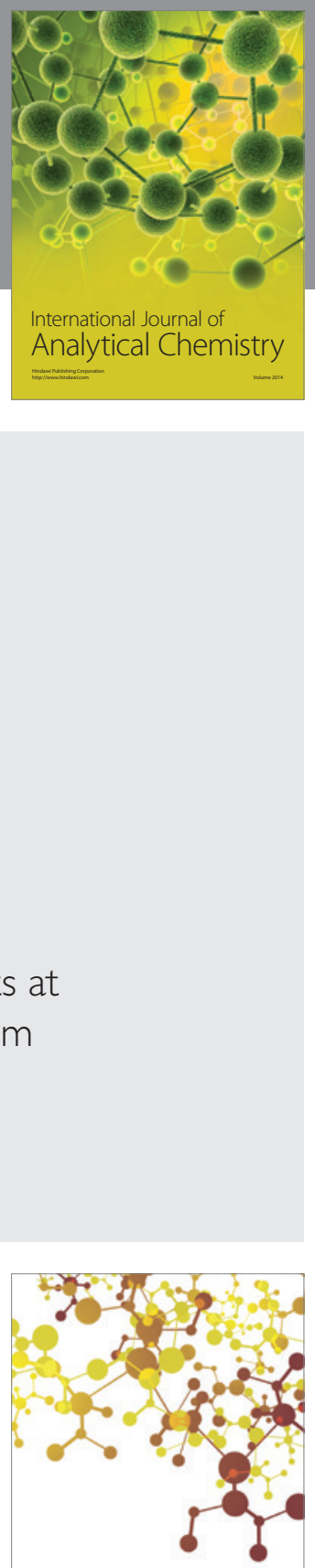

Journal of

Applied Chemistry
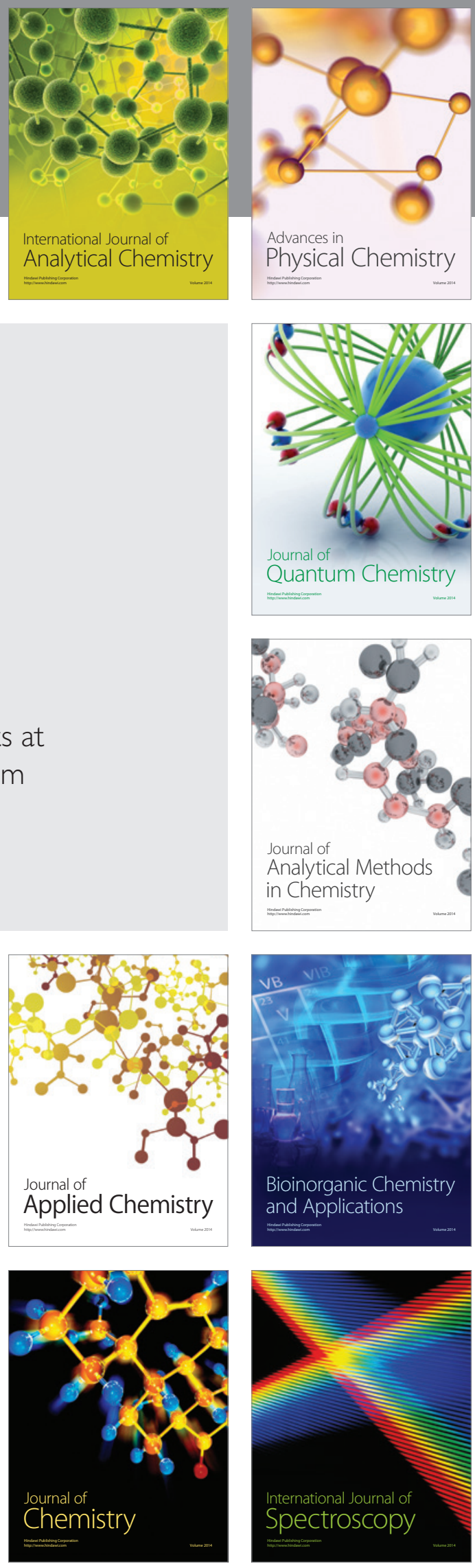